\title{
Decomposition of styrene dimers: the influence of the acid strength of the catalyst
}

\author{
M. Marczewski • E. Kamińska • H. Marczewska
}

Received: 29 June 2012/ Accepted: 20 August 2012/Published online: 9 September 2012

(C) The Author(s) 2012. This article is published with open access at Springerlink.com

\begin{abstract}
A relation between the acid strength of the active centers of sulfated alumina catalysts and the results of transformation of styrene dimers was studied. The acid strength measurements were performed according to the test reaction method using $\alpha$-methylstyrene, styrene, tert-butylbenzene and cumene reactions at $298 \mathrm{~K}$. It was found that acid strength of: alumina is characterized by $\mathrm{H}_{\mathrm{O}}>-2.2$; $\gamma-\mathrm{Al}_{2} \mathrm{O}_{3} / \mathrm{SO}_{4}{ }^{2-}(1 \%)$ is within the range of $-3.5<\mathrm{H}_{\mathrm{O}} \leq-2.2 ; \gamma-\mathrm{Al}_{2} \mathrm{O}_{3} / \mathrm{SO}_{4}{ }^{2-}$ (2-3\%) is found to be $\mathrm{H}_{\mathrm{O}} \leq-3.5$; and $\mathrm{H}_{\mathrm{O}}<-3.5$ is true for $\gamma-\mathrm{Al}_{2} \mathrm{O}_{3} / \mathrm{SO}_{4}{ }^{2-}$ (4-9\%). Cracking of styrene dimers $(573 \mathrm{~K})$ took place if the active acid sites possessed sufficient strength. The use of the catalyst of medium acidity $(-3.5$ $<\mathrm{H}_{\mathrm{O}} \leq-2.2$ ) allowed to transform them selectively (96\%) into benzene and alkylbenzenes. When the acid strength of the catalyst was higher $\left(\mathrm{H}_{\mathrm{O}} \leq-3.5\right)$, the selectivity of the reaction changed. The selectivity of benzene and its derivatives diminished (to $65 \%$ ) and dicyclic compounds (indane and indene derivatives) appeared (selectivity $21 \%$ ) among the reaction products.
\end{abstract}

Keywords Polystyrene decomposition $\cdot$ Sulfated alumina $\cdot$ Acid strength

\section{Introduction}

A growing accumulation of polymer wastes on landfills is one of the most important challenges for chemical technology. Chemical recycling is one of the solutions of this problem. It allows to recover the monomers or to convert wastes into new compounds of higher utility. In the case of polystyrene (PS), catalytic cracking is the most promising method which can be applied in the chemical recycling. At high cracking

M. Marczewski $(\bowtie) \cdot$ E. Kamińska $\cdot$ H. Marczewska

Chemistry Department, Warsaw University of Technology, Noakowskiego 3,

00-662 Warsaw, Poland

e-mail: marekm@ch.pw.edu.pl 
temperature (673-773 K), PS thermally decomposes forming a mixture of oligomers (dimers, trimers, tetramers...), which subsequently undergo catalytic transformation $[1,2]$. Solid acids have been frequently used as PS cracking catalysts [3, 4]. They are able to protonate styrene oligomers with the formation of reactive carbenium ions.

In the case of 1,3 diphenyl-1-butene (styrene dimer), the reaction begins with (Scheme 1) a Brønsted acid center attack on the unsaturated carbon chain (I) of the dimer or on the aromatic ring. As a result the different carbenium ions (II), (III) and (IV) are formed and then they react according to the diverse pathways. The carbocation (II) dealkylates to benzene and highly unsaturated aliphatic species - coke precursors. Carbenium ions (III) and (IV) undergo complex transformation ( $\beta$-cleavage followed by hydrogen transfer) forming toluene, $\alpha$-methylstyrene and cumene as well as styrene and ethylbenzene. Intramolecular alkylation of (IV) results in the formation of cyclic styrene dimers, i.e. 1-phenyl-3-methylindane. The latter, under the action of Brønsted acid sites, dealkylates to benzene and methylindene, which subsequently converts into naphthalene. All these transformation have been already demonstrated. In PS cracking products, styrene oligomers as well as benzene, toluene, styrene, ethylbenzene, cumene and indane, indene and naphthalene derivatives were observed [3-5]. Haw [6] reported that the cyclic styrene dimer adsorbed in the structure of HZSM-5 at $373 \mathrm{~K}$ dealkylates into benzene and methylindyl cation, which forms naphthalene at elevated temperature.

When analyzing the works on PS decomposition, it is difficult to find information on the influence on the selectivity of PS acid catalyzed cracking. One can expect that the acid strength of the active centers should be an important factor affecting the reaction. It is then interesting to relate the acid strength of catalysts with the results of PS cracking.

The acid strength of solids can be measured applying different methods [7]. The most used such methods are based on Hammett indicator adsorption [6, 7], adsorption of probe molecules examined with calorimetric [7, 8], thermoprogrammed desorption (TPD) [7, 9, 10] and NMR [6] measurements. The acid strength can be also estimated by means of the test reaction method [11, 12]. This method allows the measurement of the relative acid strength of a catalyst on the basis of the results of reactions which need sites of defined acid strength for their initiation. Suitable reactants for the test reactions can be for example alkyl and alkenyl benzene derivatives such as $\alpha$-methylstyrene, styrene, tert-butylbenzene and cumene. They differ in proton affinity (PA) [13-15] as well as in the order of resulting proton addition in the corresponding carbenium ions (Scheme 2).

When analyzing the properties of these compounds, one can conclude that $\alpha$-methylstyrene is the reactant that very easily undergoes protonation and then a reaction (the highest value of PA, very stable tertiary methylstyryl cation), the next one is styrene (lower PA, stable secondary styryl cation) then tert-butylbenzene (lower PA, tertiary tert-butyl cation). Cumene should be the least reactive because it possesses as low a PA value as tert-butylbenzene, but forms the less stable secondary propyl cation upon protonation. The use of such reactant set should allow the detection of the existence of weak acid centers ( $\alpha$-methylstyrene transformation), medium strength sites (styrene reaction), strong acid centers (tert-butylbenzene reaction) and very strong protic sites (cumene transformation). 
The aim of this work was to study the influence of catalyst acid strength on the cracking of styrene oligomers-the main reaction in PS decomposition. As catalysts, sulfated aluminas with different $\mathrm{SO}_{4}{ }^{2-}$ concentration were used. Sulfated alumina is a solid acid of high acid strength [16], which can even pass superacid limits $[17,18]$. In our previous work [19], we showed that the acid strength of the $\gamma-\mathrm{Al}_{2} \mathrm{O}_{3} / \mathrm{SO}_{4}{ }^{2-}$ system strongly depends on the concentration of sulfuric acid. Acid strength was measured using the test reaction method. As reactants, compounds of diverse structures like 1-hexane, cyclohexene, 3-metylpentane, methylcycloheksane, pentane, toluene, ethylbenzene, cumene, toluene and low alcohols of different orders were used. Such a broad set of substrates forced us to use different reaction conditions: a batch reactor, a low temperature of $333 \mathrm{~K}$ (n-pentane, 3-methylpentane) or a flow reactor and an elevated temperature of $523 \mathrm{~K}$ (aromatic compounds). Moreover, the use of $\mathrm{H}_{2} \mathrm{O}$ producing test reactions (alkylation of aromatics with alcohols) could modify the measured acidity of examined catalysts. Hence, the obtained results could not precisely reflect the differences in the acid strength of the examined catalysts. In order to avoid similar problems, we decided to characterize the acid properties of the $\gamma-\mathrm{Al}_{2} \mathrm{O}_{3} / \mathrm{SO}_{4}{ }^{2-}$ system using compounds that do not differ much in their structures such as $\alpha$-methylstyrene, styrene, tert-butylbenzene and cumene and unified reaction conditions (a batch reactor, ambient temperature). Moreover, the chosen test reactants possess structures close to styrene oligomers and all undergo activation in the presence of acid sites like styrene oligomers.

\section{Experimental}

The catalysts

Sulfated alumina. $\gamma-\mathrm{Al}_{2} \mathrm{O}_{3}$ (ABCR Karlsruhe, $\mathrm{S}_{\mathrm{BET}} 206 \mathrm{~m}^{2} / \mathrm{g}, 1.02-1.20 \mathrm{~mm}$ grain fraction) was impregnated using the incipient wetness method with sulfuric acid solutions. The solution concentrations were matched to obtain the catalyst containing from 1 to $9 \mathrm{wt} \%$ of $\mathrm{SO}_{4}{ }^{2-}$. The obtained substances were dried at 333 and $383 \mathrm{~K}$ for $24 \mathrm{~h}$ and then calcined at $753 \mathrm{~K}$ in the stream of dry air for another $24 \mathrm{~h}$. Silica-alumina $\left(87 \% \mathrm{SiO}_{2}-13 \% \mathrm{Al}_{2} \mathrm{O}_{3}\right.$, Ventron $\mathrm{GmBH}, \mathrm{S}_{\mathrm{BET}} 392 \mathrm{~m}^{2} / \mathrm{g}$, $1.02-1.20 \mathrm{~mm}$ grain fraction) was used as a reference catalyst.

\section{Acid strength measurements}

Before the reaction, a catalyst sample $(0.5 \mathrm{~g})$ was placed in a glass batch reactor $\left(76 \mathrm{~cm}^{3}\right)$ connected to a vacuum/dry air line and calcined at $753 \mathrm{~K}$ for $20 \mathrm{~h}$ in a stream of dry air. The reactor was then cooled to the desired temperature, closed and the substrates injected $\left(1 \mathrm{~cm}^{3}\right)$. After $20 \mathrm{~h}$, the reaction products were analyzed.

Synthesis of styrene dimers

$20 \mathrm{~g}$ of $\mathrm{SiO}_{2}$ was initially impregnated with $42 \mathrm{~cm}^{3}$ of $72 \% \mathrm{H}_{2} \mathrm{SO}_{4}$ solution in a $500 \mathrm{~cm}^{3}$ three-neck flask equipped with a magnetic stirrer, a reflux coil condenser 
and heating mantle then $200 \mathrm{~cm}^{3}$ of styrene added. The reacting system was heated at $383-423 \mathrm{~K}$ with stirring for $6 \mathrm{~h}$. The cooled reaction product was placed in a separating funnel. The spent catalyst was washed twice with diethyl ether $\left(2 \times 50 \mathrm{~cm}^{3}\right)$ and the solution added to the reaction products. The collected products were washed with sodium hydrogen carbonate solution $\left(2 \times 60 \mathrm{~cm}^{3}\right)$ in order to neutralize sulfuric acid. The organic phase was separated and dried with anhydrous calcium chloride, filtered with a Buchner funnel and distilled. The resulting product contained polystyrene dimers $(91.2 \mathrm{wt} \%)$, trimers $(7.8 \mathrm{wt} \%)$ and tetramers $(1.0 \mathrm{wt} \%)$. To obtain the reaction substrate, it was diluted with $n$-heptane in a 1:1 molar proportion.

Reactions of styrene dimers

The reactions were performed in a flow reactor. The catalyst $\left(2 \mathrm{~cm}^{3}\right)$ was placed in the reactor and heated for $24 \mathrm{~h}$ at $753 \mathrm{~K}$ in a stream of dry air. After catalyst activation, the reactor was cooled to the desired temperature (from 473 to $753 \mathrm{~K}$ ) and the reactant was fed into it with an infusion pump at $3.6 \mathrm{~cm}^{3} / \mathrm{h}$ for $60 \mathrm{~min}$.

\section{Materials}

All organic reactants, sulfuric acid, $\mathrm{NaHCO}_{3}, \mathrm{CaCl}_{2}$ were supplied by Aldrich.

\section{Analysis}

The obtained reaction products were analyzed in with GC (Agilent $6890 \mathrm{~N}$ with FID detector) equipped with a $30 \mathrm{~m}$ HP5 capillary column (I.D. $0.32 \mathrm{~mm}, \mathrm{~d}_{\mathrm{f}} 0.25 \mu \mathrm{m}$, temperature $343 \mathrm{~K}(5 \mathrm{~min})$, to 543 at $3 \mathrm{~K} / \mathrm{min})$.

\section{Results}

\section{Acid properties}

The acidity of $\gamma-\mathrm{Al}_{2} \mathrm{O}_{3} / \mathrm{SO}_{4}{ }^{2-}$ catalytic system depends on the surface concentration of $\mathrm{H}_{2} \mathrm{SO}_{4}$ [19]. This can be seen from the results of the test reactions (Fig. 1).

$\gamma-\mathrm{Al}_{2} \mathrm{O}_{3}$, the sulfuric acid carrier, at $293 \mathrm{~K}$ did not initiate any of the test reaction studied. The introduction of $1 \%$ of $\mathrm{H}_{2} \mathrm{SO}_{4}$ on the alumina surface resulted in the appearance of active centers that initiated $\alpha$-methylstyrene dimerization. Further increase in the sulfuric acid concentration $(\geq 2 \%)$ initiated the formation of linear dimers from styrene. The catalysts with higher than $3 \%$ amount of the acid catalyzed tert-butylbenzene disproportionation into benzene and di-tert-butylbenzenes. The $\gamma-\mathrm{Al}_{2} \mathrm{O}_{3} / \mathrm{SO}_{4}{ }^{2-}$ catalytic system was not able to initiate cumene transformation at $293 \mathrm{~K}$.

Styrene dimers underwent transformation over $\mathrm{Al}_{2} \mathrm{O}_{3}-\mathrm{H}_{2} \mathrm{SO}_{4}$ catalysts at $573 \mathrm{~K}$ (Table 1). 


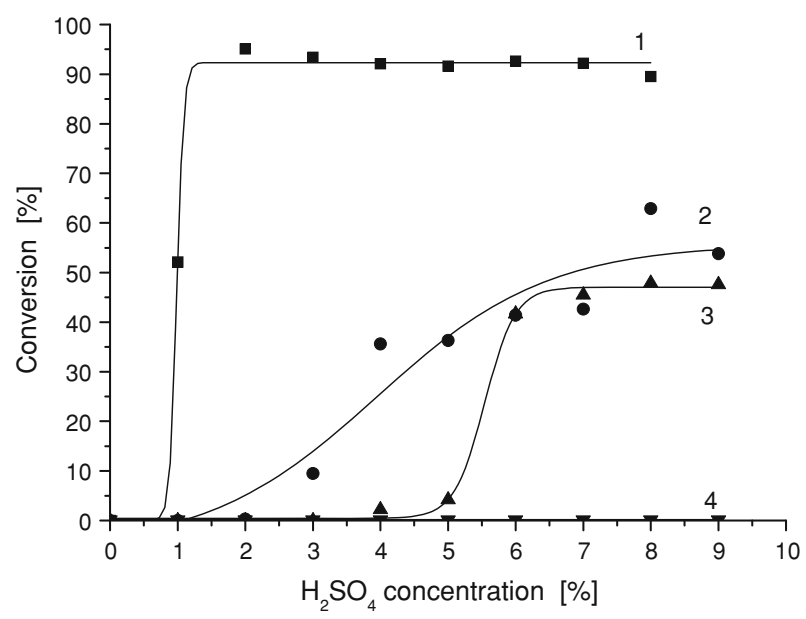

Fig. 1 Acidity of the $\gamma-\mathrm{Al}_{2} \mathrm{O}_{3} / \mathrm{SO}_{4}{ }^{2-}$ catalytic system. Test reactions conversion for $\alpha$-methylstyrene (1), styrene (2), tert-butylbenzene (3), cumene (4) (293 K, batch reactor)

$\gamma-\mathrm{Al}_{2} \mathrm{O}_{3}$ catalyzed only the double bond isomerization of styrene dimers. The selectivity to decomposition products was as low as $2 \%$. In turn, the catalyst with $1 \%$ sulfuric acid catalyzed mostly the decomposition of styrene dimers. Among the reaction products, one can observe benzene, ethylbenzene and cumene. A further increase in $\mathrm{H}_{2} \mathrm{SO}_{4}$ concentration resulted in a rise in total conversion (from 26 to $33 \%$ ) and the appearance of dicyclic products (indane and indene derivatives as well as diphenylpropenes).

\section{Discussion}

The first step of PS cracking is a thermal decomposition into the volatile oligomers. The latter undergo activation on the catalyst surface and form final reaction products [20]. The selectivity of the transformation depends on the properties of the catalyst applied. In the case of solid acids, the acid strength of Brønsted sites determines the composition of the reaction products. In the presented work, we studied the influence of acid strength of the catalysts on PS decomposition. Styrene dimers, synthesized in our laboratory as transition products of PS degradation, were chosen as substrates, while $\gamma-\mathrm{Al}_{2} \mathrm{O}_{3} / \mathrm{SO}_{4}{ }^{2-}$ solid acids of acid strength measured with the use of the test reaction method were applied as the catalysts (Scheme 1).

The active acid centers of broad acid strength range are present on the surface of $\gamma-\mathrm{Al}_{2} \mathrm{O}_{3} / \mathrm{SO}_{4}{ }^{2-}$ catalytic systems. Pure $\gamma-\mathrm{Al}_{2} \mathrm{O}_{3}$ is a very weak protic acid [21]. The catalytic activity is rather related to the presence of Lewis acid (exposed $\mathrm{Al}^{3+}$ ions) and Lewis base (surface $\mathrm{O}^{2-}$ ) pair centers [22]. The oxide surface reaction with sulfuric acid results in the formation of new Brønsted acid sites, whose strength depends on the surface concentration of $\mathrm{SO}_{4}{ }^{2-}$ anions [19]. The test reaction method was used to study the acid strength of the system. All reactants used, i.e. 


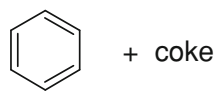<smiles></smiles>

II<smiles>C=C(C)c1ccccc1CCc1ccccc1</smiles>

III<smiles>C[C+]C</smiles><smiles>CC1C=Cc2ccccc2C1c1ccccc1</smiles><smiles>CC1C[CH+]c2ccccc2C1c1ccccc1</smiles><smiles>C=Cc1ccccc1</smiles>

I

IV

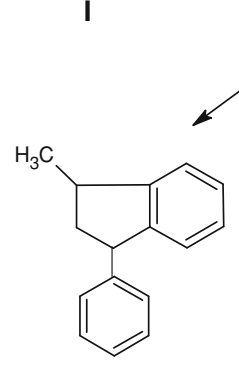

V

\section{Scheme 1}

$\alpha$-methylstyrene, styrene, tert-butylbenzene and cumene undergo protonation in the presence of acid centers of particular strength. The first two reactants convert to tertiary and secondary aliphatic carbenium ions (Scheme 2), which alkylate the neutral molecules of $\alpha$-methylstyrene and styrene and form dimeric species [23]. It has been reported that sulfuric acids solutions of 43 and $53 \%$ can catalyze these reactions at reflux temperature (403-423 K) [23]. The acid strengths of the catalysts can be easily re-calculated and presented in $\mathrm{H}_{\mathrm{O}}$ units as -2.2 and -3.5 [24]. The reaction of tert-butylbenzene is also initiated by proton addition, but on the aromatic ring (Scheme 2). The resulting carbenium ion reacts further and gives products like benzene and di-tert-butylbenzene with another substrate molecule in a disproportionation reaction. This reaction needs the action of stronger acids and can be

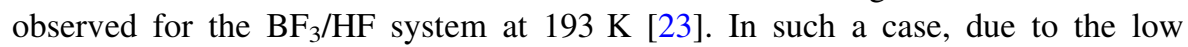
temperature, there is no simple method to evaluate the acid strength of this catalyst 
Test reaction substrate: $\alpha$-methylstyrene styrene tert-butylbenzene cumene

Proton affinity $\left[\mathrm{kJmol}^{-1}\right]$

Protonated forms:
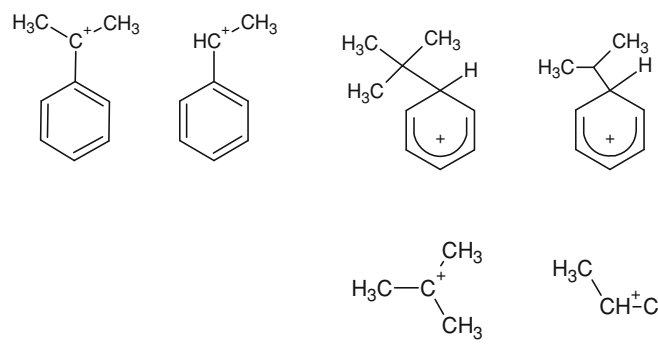

$\stackrel{\mathrm{H}_{3} \mathrm{C}}{\mathrm{C}} \mathrm{CH}_{-}^{+} \mathrm{CH}_{3}$

\section{Scheme 2}

on the $\mathrm{H}_{\mathrm{O}}$ scale. It can be only roughly approximated as $\mathrm{H}_{\mathrm{O}}$ close to -15 units. A similar transformation can be also observed for cumene, but in this case, the acid strength of the catalyst should be higher as the less stable secondary propyl cation is the transition state of the reaction. Then the results of the transformations of the above reactants, under the same reaction conditions, in the presence of the examined catalysts, should allow the estimation of their acid strength. The obtained results for the $\gamma-\mathrm{Al}_{2} \mathrm{O}_{3} / \mathrm{SO}_{4}{ }^{2-}$ system confirmed this assumption. On their basis, one can conclude that:

- alumina does not initiate any of the test reactions applied. It means that the protic centers of $\gamma-\mathrm{Al}_{2} \mathrm{O}_{3}$ are not able to protonate even the most basic $\alpha$-methylstyrene. Thus, the acid strength of alumina is lower than that of the $43 \% \mathrm{H}_{2} \mathrm{SO}_{4}$ solution at $403-423 \mathrm{~K}\left(\mathrm{H}_{\mathrm{O}}>-2.2\right)$.

- $\gamma-\mathrm{Al}_{2} \mathrm{O}_{3} / \mathrm{SO}_{4}{ }^{2-}(1 \%)$ catalyzes $\alpha$-methylstyrene dimerization, but cannot initiate styrene transformation, which occurs for the $53 \% \mathrm{H}_{2} \mathrm{SO}_{4}$ solution at $403-423 \mathrm{~K}$. Thus, its acid strength is within the range of $-3.5<\mathrm{H}_{\mathrm{O}} \leq-2.2$.

- $\gamma-\mathrm{Al}_{2} \mathrm{O}_{3} / \mathrm{SO}_{4}{ }^{2-}(2-3 \%)$ also catalyzes styrene dimerization apart from the $\alpha$-methylstyrene reaction. Hence, the acid strength of this catalyst can be expressed as $\mathrm{H}_{\mathrm{O}} \leq-3.5$.

- $\gamma-\mathrm{Al}_{2} \mathrm{O}_{3} / \mathrm{SO}_{4}{ }^{2-}(4-9 \%)$ catalyzes the transformation of all the test reaction substrates except cumene. Thus, the acid strength of active centers can even reach the acidity of the $\mathrm{BF}_{3} / \mathrm{HF}$ system at $193 \mathrm{~K}$. The presented results do not allow the precise determination of the acid strength of the $\gamma-\mathrm{Al}_{2} \mathrm{O}_{3} / \mathrm{SO}_{4}{ }^{2-}$ (4-9 \%) system. In our work [19], we estimated it at $\mathrm{H}_{\mathrm{O}}<-14$ level as the catalysts initiated low temperature $(333 \mathrm{~K})$ pentane isomerization. According to [25], this phenomenon is indicative of the presence of superacid centers, but in the other works, a different opinion has been presented. Namely, the surface $\mathrm{SO}_{\mathrm{x}}$ species of a sulfated oxide can dehydrogenate the alkane via stoichiometric reduction and then allow the strong acid sites, not necessarily superacid, to catalyze its further reaction [26]. Thus, the lower limit of the acid strength of the $\gamma-\mathrm{Al}_{2} \mathrm{O}_{3} / \mathrm{SO}_{4}{ }^{2-}(4-9 \%)$ system is at least equal to $\mathrm{H}_{\mathrm{O}}<-3.5$, but the upper acidity limit is not sure. 
Table 1 Catalytic activity of the $\gamma-\mathrm{Al}_{2} \mathrm{O}_{3} / \mathrm{SO}_{4}{ }^{2-}$ catalytic system in the transformation of the styrene dimer at $573 \mathrm{~K}$ (styrene dimer/heptane $=1 / 1$, flow reactor, LHSV $=1.8 \mathrm{~h}^{-1}$ )

\begin{tabular}{|c|c|c|c|c|c|c|c|c|c|}
\hline \multirow[t]{2}{*}{ Reaction products } & \multicolumn{9}{|c|}{$\mathrm{H}_{2} \mathrm{SO}_{4}$ concentration $(\%)$} \\
\hline & 0 & 1 & 2 & 3 & 4 & 5 & 6 & 7 & 8 \\
\hline Benzene & 0.6 & 12.9 & 26.2 & 29.5 & 28.7 & 33.5 & 28.1 & 34.4 & 29.5 \\
\hline Toluene & 0.8 & & 1.6 & 0.7 & & 1.1 & 0.4 & 1.0 & \\
\hline Ethylbenzene & 1.7 & 53.6 & 29.5 & 22.4 & 29.0 & 20.5 & 29.3 & 21.1 & 27.0 \\
\hline Styrene & 2.4 & 10.7 & - & - & - & - & - & - & - \\
\hline Cumene & - & 19.0 & 10.5 & 7.8 & 10.0 & 7.6 & 10.3 & 8.7 & 9.1 \\
\hline$\alpha$-Methylstyrene & 1.6 & - & - & - & - & - & - & - & - \\
\hline Methylindanes & - & - & 19.0 & 23.4 & 17.1 & 22.4 & 17.3 & 21.2 & 17.2 \\
\hline Methylindenes & - & - & 0.8 & 0.7 & 0.5 & 0.7 & 0.5 & - & 0.5 \\
\hline Diphenylpropene & - & - & 3.6 & 4.9 & 4.8 & 4.3 & 4.4 & 3.7 & 4.2 \\
\hline Dimers & 91.8 & 3.8 & - & 3.2 & 0.9 & 2.6 & 1.1 & 2.0 & 1.8 \\
\hline Conversion & $\begin{array}{l}27.2 \\
(2.2)^{\mathrm{a}}\end{array}$ & $\begin{array}{l}5.3 \\
(5.1)\end{array}$ & $\begin{array}{l}12.0 \\
(12.0)\end{array}$ & $\begin{array}{l}18.1 \\
(17.5)\end{array}$ & $\begin{array}{l}26.4 \\
(26.1)\end{array}$ & $\begin{array}{l}21.6 \\
(21.0)\end{array}$ & $\begin{array}{l}26.4 \\
(26.1)\end{array}$ & $\begin{array}{l}25.1 \\
(24.6)\end{array}$ & $\begin{array}{l}23.3 \\
(22.9)\end{array}$ \\
\hline
\end{tabular}

${ }^{a}$ Conversion into decomposition products

In the presence of such characterized catalysts, the transformation of styrene dimers at $573 \mathrm{~K}$ were studied. Detailed results have been already presented (Table 1) and are summarized in Table 2.

The results indicate that if the acid strength of active centers is too low $\left(\mathrm{H}_{\mathrm{O}}>\right.$ -2.2 ), the styrene dimer does not decompose. The ultimate reaction is double bond isomerization in the aliphatic chain of the dimer catalyzed by Lewis acid and Lewis base sites. When the acid strength of the active sites increases to the values from $-3.5<\mathrm{H}_{\mathrm{O}} \leq-2.2$ interval, the styrene dimers are protonated in the aliphatic unsaturated chain as well as in the aromatic ring (cations II and III, Scheme 1) and begin to dealkylate and decompose. A further rise of acid strength $\left(\mathrm{H}_{\mathrm{O}} \leq-3.5\right)$ of

Table 2 Catalytic activity of Brønsted acid centers in the transformation of the styrene dimer at $573 \mathrm{~K}$

\begin{tabular}{lllc}
\hline Catalyst & Acid strength & Styrene dimer reactions (selectivity) & Active centers \\
\hline$\gamma-\mathrm{Al}_{2} \mathrm{O}_{3}$ & $\mathrm{H}_{\mathrm{O}}>-2.2$ & Isomerization $(92 \%)$ & $\begin{array}{c}\text { Lewis acid and } \\
\text { basic }\end{array}$ \\
$\gamma-\mathrm{Al}_{2} \mathrm{O}_{3} / \mathrm{SO}_{4}{ }^{2-}$ & $-3.5<\mathrm{H}_{\mathrm{O}} \leq$ & Dealkylation $(13 \%)$, cracking $(83 \%)$ & $\begin{array}{c}\text { Brønsted acid } \\
\text { centers }\end{array}$ \\
$(1 \%)$ & -2.2 & Dealkylation $(34 \%)$, cracking $(31 \%)$ & $\begin{array}{c}\text { Brønsted acid } \\
\text { and cyclization }(21 \%)^{\mathrm{b}}\end{array}$ \\
$\gamma-\mathrm{Al}_{2} \mathrm{O}_{3} / \mathrm{SO}_{4}{ }^{2-}$ & $\mathrm{H}_{\mathrm{O}} \leq-3.5$ & as above & as above \\
$(2-3 \%)$ & $\mathrm{H}_{\mathrm{O}}<-3.5^{\mathrm{a}}$ & & \\
$\gamma-\mathrm{Al}_{2} \mathrm{O}_{3} / \mathrm{SO}_{4}{ }^{2-}$ & & & \\
$(4-9 \%)$ & & & \\
\hline
\end{tabular}

\footnotetext{
${ }^{a}$ The upper limit of acid strength can reach superacid region $\left(\mathrm{H}_{\mathrm{O}}>-14\right)$

${ }^{\mathrm{b}}$ Results for the $\gamma-\mathrm{Al}_{2} \mathrm{O}_{3} / \mathrm{SO}_{4}{ }^{2-}(5 \%)$ catalyst
} 
Table 3 Catalytic activity of the $\mathrm{SiO}_{2}-\mathrm{Al}_{2} \mathrm{O}_{3}(13 \%)$ solid acid in the transformation of the styrene dimer at $573 \mathrm{~K}$ (styrene dimer/heptane $=1 / 1$, flow reactor, LHSV $=1.8 \mathrm{~h}^{-1}$ )

\begin{tabular}{ll}
\hline Test reactions & \\
\hline Reactant & Conversion (\%) \\
\hline$\alpha$-Methylstyrene & 32.5 \\
Styrene & 14.1 \\
Tert-butylbenzene & - \\
\hline Styrene oligomer reaction & \\
\hline Product & Selectivity (\%) \\
\hline Benzene & 38.2 \\
Toluene & 0.5 \\
Ethylbenzene & 22.4 \\
Styrene & - \\
Cumene & 2.3 \\
$\alpha$-Methylstyrene & - \\
Methylindanes & 27.2 \\
Methylindene & 1.1 \\
Diphenylpropene & 1.5 \\
Dimers & 0.7 \\
Conversion & $41.9(41.6)^{\mathrm{a}}$ \\
\hline
\end{tabular}

a Conversion into decomposition products

the active centers allows an internal alkylation (cyclization) of the cation IV (Scheme 1) to proceed with the formation of indane and indene derivatives. The presence of more acidic active sites $\left(\mathrm{H}_{\mathrm{O}}<-3.5\right)$ does not change the reaction pathways of styrene dimers.

In order to confirm the above conclusions, the reaction of the styrene dimers was performed over a different type of solid acid, $\mathrm{SiO}_{2}-\mathrm{Al}_{2} \mathrm{O}_{3}(13 \%)$ (Table 3).

This catalyst possesses Brønsted acid centers, whose acid strength allows to catalyze only $\alpha$-methylstyrene and styrene reactions at $298 \mathrm{~K}$, but not tertbutylbenzene disproportionation. Hence, its acid strength is similar to the $\gamma-\mathrm{Al}_{2} \mathrm{O}_{3}$ / $\mathrm{SO}_{4}{ }^{2-}(2-3 \%)$ catalysts. The silica-alumina $\mathrm{SiO}_{2}-\mathrm{Al}_{2} \mathrm{O}_{3}(13 \%)$ catalyzes the decomposition of styrene dimers into the same products as sulfated alumina with similar selectivities. The higher conversion observed may be due to the higher concentration of acid with the strength of $\mathrm{H}_{\mathrm{O}} \leq-3.5$ on the silica-alumina surface.

\section{Conclusions}

The obtained results show that there is a relation between the acid strength of active centers and the results of the transformation of styrene dimers. The cracking of styrene dimers takes place at $573 \mathrm{~K}$ if the active sites possess sufficient strength. Namely, the use of the catalyst of medium acidity $\left(-3.5<\mathrm{H}_{\mathrm{O}} \leq-2.2\right)$ allows to obtain benzene and alkylbenzenes selectively (96\%). When the acid strength of the catalyst is higher $\left(\mathrm{H}_{\mathrm{O}} \leq-3.5\right)$, the selectivity of the transformation changes. The 
formation of benzene and its derivatives diminishes (to $65 \%$ ), and dicyclic compounds (indane and indene derivatives) appear among the reaction products (selectivity $21 \%$ ).

Acknowledgments This work was sponsored by Polish Ministry of Education (project no. NN209 084338), 2010-2013.

Open Access This article is distributed under the terms of the Creative Commons Attribution License which permits any use, distribution, and reproduction in any medium, provided the original author(s) and the source are credited.

\section{References}

1. Guaita M, Chiantore O, Costa L (1985) Polym Degrad Stab 12:315-323

2. Saido K, Taguch H, Kodera Y, Ishihava Y, Ryu IJ, Chung SY (2003) Macromol Res 11:87-91

3. Audisio G, Bertini F, Beltrame PL, Carniti P (1990) Polym Degrad Stab 29:191-200

4. Tae J-W, Jang B-S, Kim J-R, Kim I, Park D-W (2004) Solid State Ion 172:129-133

5. Lin R, White LR (1996) ACS Preprints Div Fuel Chem 41:1165-1169

6. Haw JF, Nicholas JB, Xu T, Beck LW, Ferguson DB (1996) Acc Chem Res 29:259-267

7. Corma A (1995) Chem Rev 95:559-614

8. Auroux A (2008) In: Karge HG, Weitkamp J (eds) Acidity and basicity, molecular sieves, vol 6. Springer, Berlin, pp 153-212

9. Katada N, Tsubaki T, Niwa M (2008) Appl Catal A 340:76-86

10. Katada N, Endo J, Notsu K, Yasunobu N, Naito N, Niwa M (2000) J Phys Chem B 104:10321-10328

11. Lercher JA, Jentys A, Brait A (2008) In: Karge HG, Weitkamp J (eds) Acidity and basicity, molecular sieves, vol 6. Springer, Berlin, pp 153-212

12. Guisnet M (1990) Acc Chem Res 23:392-398

13. Greenberg A, Liebman JF (1982) J Org Chem 47:2084-2088

14. Hunter EPI, Lias SG (1998) J Phys Chem Ref Data 27:413-656

15. Kolbe S (2011) J Phys Chem A 115:3106-3115

16. Gawthrope DE, Lea AF, Wilson K (2004) Phys Chem Chem Phys 6:3907-3914

17. Arata K, Matsuhashi H, Hino M, Nakamura H (2003) Catal Today 81:17-30

18. Yang T, Chang T, Yeh Ch (1995) J Mol Catal A: Chem 115:339-346

19. Marczewski M, Jakubiak A, Marczewska H, Frydrych A, Gontarz A, Śnieguła A (2004) Phys Chem Chem Phys 6:2513-2522

20. Woo OS, Ayala N, Broadbelt LJ (2000) Catal Today 55:161-171

21. Marcilly C (2006) Acido-basic catalysis. Editions TECNIP, Paris, p. 93

22. Pines H, Manassen J (1966) Adv Catal 16:49

23. Pines H (1981) The chemistry of catalytic hydrocarbon conversions. Academic Press, New York p 43

24. Johnson DC, Katritzky AR, Shapiro SA (1969) J Am Chem Soc 91:6654-6662

25. Arata K (1990) Adv Catal 37:165

26. Macht J, Carr RT, Iglesia E (2009) J Catal 264:54-66 